\title{
Recurrence of Choroid Plexus Papilloma with Malignant Transformation
}

\section{-Case Report and Lectin Histochemistry Study-}

\author{
Shuji NiIKawa, Takeshi ITO, Takatsugu MURAKawa, Hiroshi HiRAYAMA, \\ Takashi ANDO, Noboru SAKAI and Hiromu YAMADA
}

Department of Neurosurgery, Gifu University School of Medicine, Gifu

\begin{abstract}
A very rare primary choroid plexus carcinoma occurred in a 44-year-old male presenting with occipitalgia, nausea, and blurred vision. The tumor had progressed from a choroid plexus papilloma in the fourth ventricle which was totally removed 6 years previously. Lectin histochemistry might be useful for the differential diagnosis of primary choroid plexus neoplasms and other brain tumors such as secondary carcinoma.
\end{abstract}

Key words: choroid plexus neoplasm, malignant transformation, lectin histochemistry

\section{Introduction}

Primary choroid plexus neoplasms are rare, comprising $0.4-0.6 \%$ of all intracranial tumors, $2,10,14)$ while choroid plexus carcinomas are even more infrequent. ${ }^{3,5,8,10,12,14)}$ Diagnosis of primary choroid plexus carcinoma is difficult, despite certain morphological characteristics visible by conventional light microscopy. ${ }^{8,14)}$ Infiltration, implantation, or seeding into the subarachnoid space occurs in both benign and malignant choroid plexus neoplasms, ${ }^{1,5,6,8,14)}$ and cannot therefore be considered evidence of malignancy. Choroid plexus carcinoma may be confused with gliomas such as ependymoma, and with metastatic carcinoma. ${ }^{1,3,5,8,12,14)}$ Lectin histochemistry using peanut agglutinin may be useful in the differential diagnosis of primary and secondary choroid plexus neoplasms. ${ }^{11,15)}$

Here, we present a patient with choroid plexus carcinoma which progressed from choroid plexus papilloma, and discuss the usefulness of lectin histochemistry in the diagnosis.

\section{Case Report}

A 38-year-old male, previously in good health, was

Received February 18, 1992; Accepted June 10,
1992

admitted to the Gifu University Hospital in December, 1984 with pulsatile occipitalgia and nausea persisting for several days. A general physical examination revealed no abnormalities, and no apparent neurological deficit was observed. Precontrast computed tomographic (CT) scans showed a mass in the fourth ventricle which was homogeneously enhanced postcontrast (Fig. 1 left). The neoplastic lesion was totally removed via a suboccipital craniectomy on January 29,1985 , after emplacement of a ventriculoperitoneal shunt (Fig. 1 right). Histological examination of the surgical specimen confirmed papillary structures composed of a single layer of columnar epithelium supported by a stroma of vascularized connective tissues (Fig. 2 left). The diagnosis was a choroid plexus papilloma.

He remained well until November, 1990 when occipitalgia and nausea developed again, as well as blurred vision. On the second admission, neurological examination revealed mild disorientation and choked disk. Cytological examination of the cerebrospinal fluid obtained from the shunt system discovered no malignant cells. A plain chest $x$-ray film was unremarkable. CT scans and magnetic resonance (MR) images showed two separate mass lesions with homogeneous enhancement: one in the suprasellar region and the other in the left cerebellopontine angle (Fig. 3). Tumor invasion into the surrounding brain was suspected. 

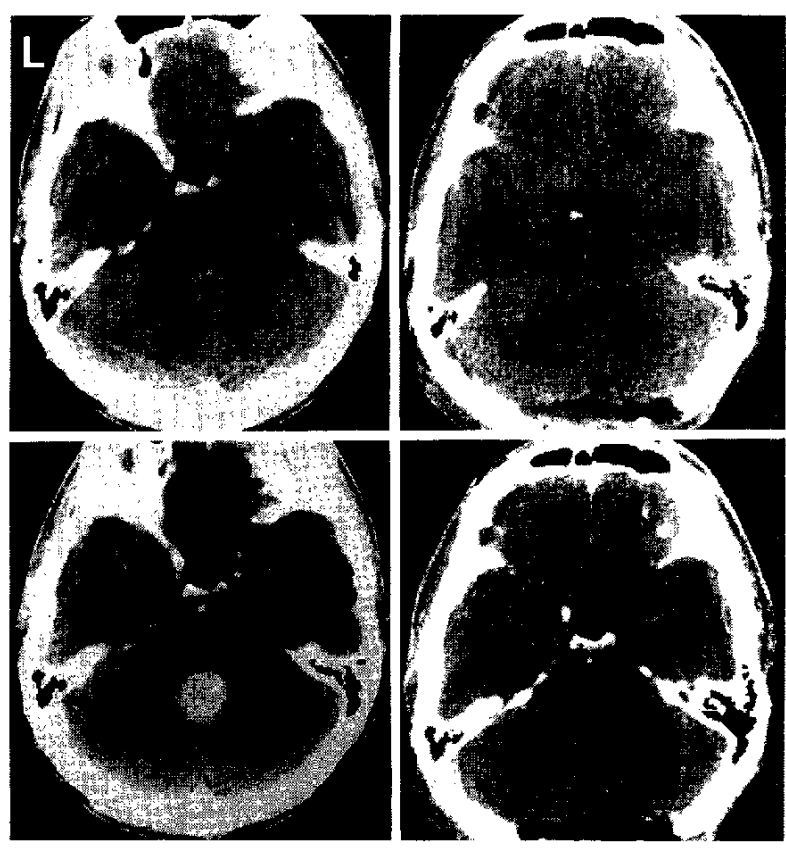

Fig. 1 Pre- (upper) and postcontrast (lower) CT scans before (left) and after (right) surgery, showing a homogeneously enhanced lesion in the fourth ventricle which was totally removed.

The suprasellar tumor was removed subtotally through a frontotemporal craniotomy on December 11, 1990. Six weeks later, the cerebellopontine angle tumor was partially removed, as the lower cranial nerves were totally enclosed. Histological examination of the specimen revealed papillary architecture of choroid plexus tissue with areas consisting of sheets of densely packed and atypical epithelial cells. The tumor cells varied considerably in size and appearance, with hyperchromatic nuclei occasionally containing mitotic figures (Fig. 2 right).

A lectin histochemistry study was performed using tissue from the original and the recurrent tumors.

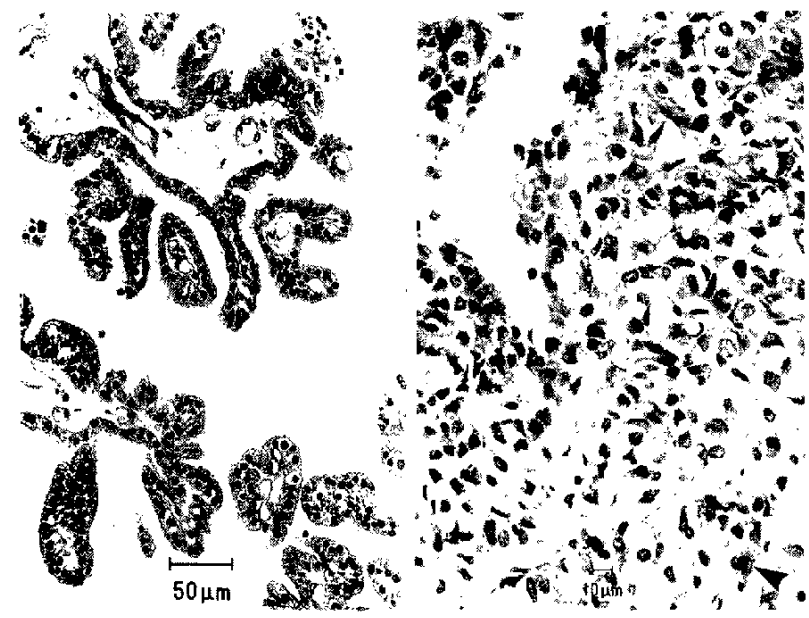

Fig. 2 left: Photomicrograph of the original tumor specimen, revealing papillary growth of single or partly pseudostratified layers of columnar epithelium, indicating a choroid plexus papilloma. HE stain, $\times 112$. right: Photomicrograph of the recurrent tumor specimen, revealing the transition from more normalappearing choroidal epithelial cells to densely packed and atypical epithelial cells with occasional mitotic figures (arrowhead). HE stain, $\times 170$.

Biotin-labeled peanut agglutinin (EY Lab., San Mateo, Cal., U.S.A.) was used in the avidin-biotin peroxidase complex method. ${ }^{13)}$ Another two samples of choroid plexus neoplasm ( 1 malignant and 1 benign) from adults were also studied for comparison. Peanut agglutinin staining was negative or weak in all four samples, but reactivity was intense after treatment with neuraminidase (Sigma, St. Louis, Mo., U.S.A.) (Fig. 4).

The postoperative course was uneventful, but MR images revealed a lumbar spinal lesion (Fig. 5). He received $54 \mathrm{~Gy}$ Lineac irradiation to the whole brain
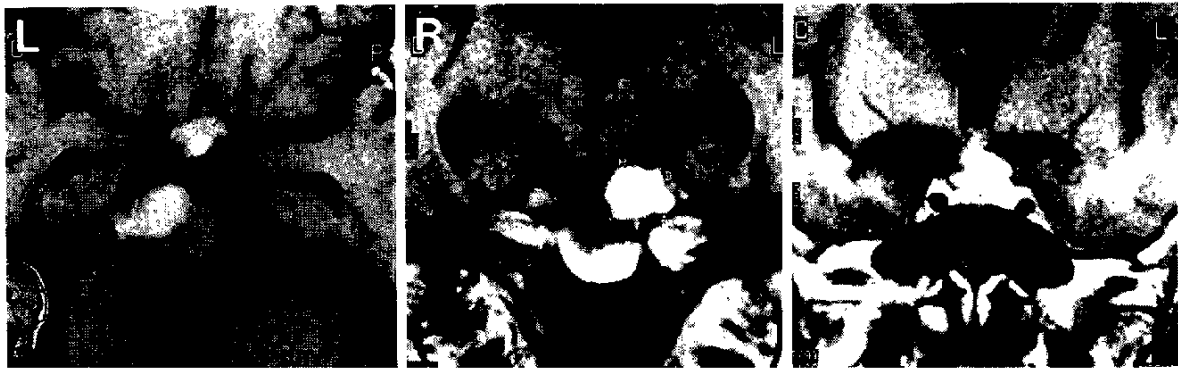

Fig. 3 Axial (left) and coronal (center, right) MR images of the head, demonstrating two separate recurrent lesions: one in the suprasellar region and the other in the cerebellopontine angle. 

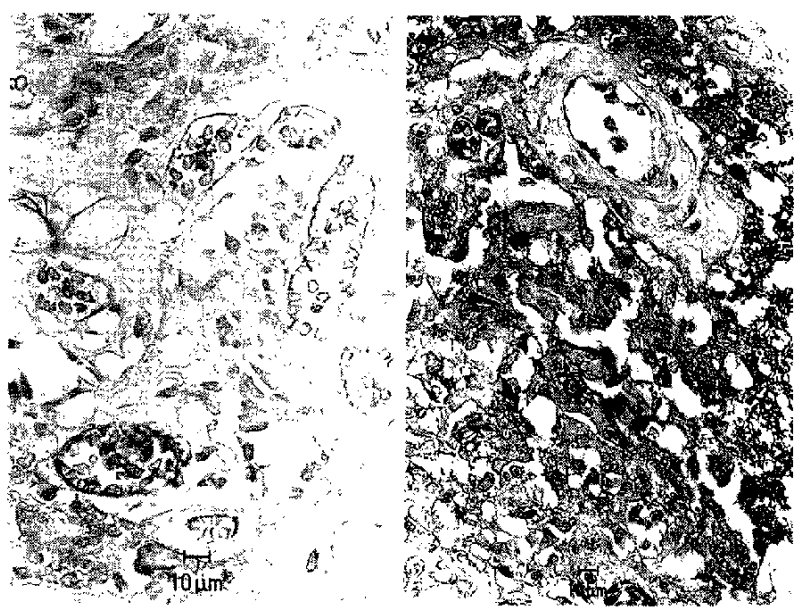

Fig. 4 Peanut agglutinin histochemical study of the recurrent tumor. left: Before neuraminidase treatment, only the vascular endothelia and erythrocytes were stained, but not neoplastic cells. $\times 225$, right: After neuraminidase pretreatment, the neoplastic cells also showed intense reactivity. $\times 170$.

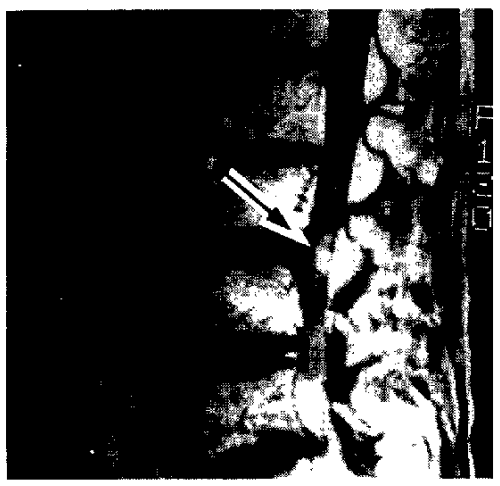

Fig. 5 Spinal MR image, demonstrating a lumbar lesion (arrow).

and $30 \mathrm{~Gy}$ locally to the lumbar spine. He was discharged 3 months after the last operation with a mild limb ataxia. He is doing well, although followup MR images revealed that the residual tumor in the cerebellopontine angle had not reduced in size 8 months after discharge.

\section{Discussion}

Malignant transformation of choroid plexus papilloma $^{9,14)}$ is very rare. Russell and Rubinstein ${ }^{14)}$ reported two pediatric cases which recurred with increased cytological malignancy 8 and 11 months after subtotal removal of the original papilloma. Masuzawa et al. ${ }^{9)}$ reported an 11-year-old child, in whom a fourth ventricle papilloma became malignant 4 years after subtotal removal of the original papilloma. Although the mechanism of malignant transformation is unclear, choroid plexus papillomas do become malignant. Our case was exceptional in that the original papilloma had been totally removed, and recurrence was very delayed compared with other reported cases.

Differential diagnosis of choroid plexus carcinoma in adult cases requires great care, as it may be confused with metastasis from adenocarcinoma. ${ }^{14)}$ Electron microscope and immunohistochemical methods are helpful for the diagnosis of choroid plexus neoplasms, ${ }^{4,7,9,10,12)}$ and lectin histochemistry is useful for the differential diagnosis of primary and secondary choroid plexus neoplasms. Several authors ${ }^{11,15}$ have studied the binding sites of peanut agglutinin on human brain tumors. Primary choroid plexus neoplasms become positive with peanut agglutinin after neuraminidase pretreatment, in contrast with brain tumors such as gliomas or secondary brain lesions. Ours and two other choroid plexus neoplasms showed markedly increased reactivity to peanut agglutinin after neuraminidase treatment. This result is characteristic of primary choroid plexus neoplasms and is helpful in differential diagnosis.

\section{References}

1) Ausman JI, Shrontz C, Chason J, Knighton RS, Pak H, Patel S: Aggressive choroid plexus papilloma. Surg Neurol 22: 472-476, 1984

2) Bohm E, Strang R: Choroid plexus papillomas. $J$ Neurosurg 18: 493-500, 1961

3) Boyd MC, Steinbok P: Choroid plexus tumors: Problems in diagnosis and management. I Neurosurg 66: 800-805, 1987

4) Coons S, Johnson PC, Dickman CA, Rekate H: Choroid plexus carcinoma in siblings: A study by light and electron microscopy with $\mathrm{Ki}-67$ immunocytochemistry. $J$ Neuropathol Exp Neurol 48: 483-493, 1989

5) Dohrmann GJ, Collias JC: Choroid plexus carcinoma. Case report. J Neurosurg 43: 225-232, 1975

6) Enomoto $\mathrm{H}$, Mizuno $M$, Katsumata $T$, Doi $T$ : Intracranial metastasis of a choroid plexus papilloma originating in the cerebellopontine angle region: A case report. Surg Neurol 36: 54-58, 1991

7) Imaya H, Kudo M: Malignant choroid plexus papilloma of the fourth ventricle. Childs Nerv Syst 7: $109-111,1991$

8) Lewis P: Carcinoma of the choroid plexus. Brain 90 : $177-186,1967$ 
9) Masuzawa T, Shimabukuro H, Yoshimizu N, Sato F: Ultrastructure of disseminated choroid plexus papilloma. Acta Neuropathol (Berl) 54: 321-324, 1981

10) Matsuda M, Uzura S, Nakasu S, Handa J: Primary carcinoma of the choroid plexus in the lateral ventricle. Surg Neurol 36: 294-299, 1991

11) Mueller $W$, Klein PJ, Vierbuchen MJ, Uhlenbruck $\mathrm{G}$ : Lectin binding sites in the choroid plexus and choroid plexus papillomas. Neurosurg Rev 3: 57-65, 1980

12) Nakashima N, Goto $K$, Takeuchi J: Papillary carcinoma of choroid plexus. Light and electron microscopic study. Virchows Arch [Pathol Anat] 395: 303-318, 1982

13) Niikawa $S$, Hara A, Ando $T$, Sakai $N$, Yamada $H$, Shimokawa K: Dolichos biflorus agglutinin (DBA) binding to intracranial germ-cell tumors: detection of embryonal components in germinomas. Acta Neuropathol (Berl) 83: 347-351, 1992

14) Russell DS, Rubinstein LJ: Pathology of Tumours of the Nervous System, ed 5. London, Edward Arnold, 1989, pp 394-404

15) Schwechheimer K, Schnabel P, Moeller P: Immunohistochemical localization of peanut lectin binding sites on human brain tumors as determined by peroxidase-antiperoxidase technique in paraffin sections. Acta Neuropathol (Berl) 61: 21-26, 1983

Address reprint requests to: S. Niikawa, M.D., Department of Neurosurgery, Gifu University School of Medicine, 40 Tsukasa-machi, Gifu 500, Japan. 